\title{
ARQUITETURAS FUNERÁRIAS, MATERIAIS DE CONSTRUÇÃO E INTERAÇÃO COM O ESPAÇO NA IDADE DO BRONZE DA SERRA DA FREITA (CENTRO-NORTE DE PORTUGAL). O CASO DO TUMULUS DE LACEIRAS DO CÔVO 3, VALE DE CAMBRA
}

\author{
EDITE SÁ ${ }^{(1)}$, ANA M. S. BETTENCOURT ${ }^{(2)} \&$ PEDRO PIMENTA SIMÕES ${ }^{(3)}$
}

Resumo:

Pretende-se com este artigo dar a conhecer os resultados dos trabalhos arqueológicos levados a cabo no monumento funerário de Laceiras do Côvo 3, estrutura tumular enquadrável, provavelmente, na Idade do Bronze, localizada na freguesia de Arões, concelho de Vale de Cambra. Este monumento revela-se de particular interesse pela policromia intencional na matéria usada na sua construção e pela disposição cuidada dos elementos litológicos do tumulus, em que nada parece estar ao acaso. Tais características sugerem a intenção de manter o espaço dos mortos visível, assim como uma interligação simbólica entre rochas e minerais e as práticas relacionadas com a morte. Na linha de Tim Ingold (2000) consideramos, ainda, que a matéria do monumento seria portadora de determinadas propriedades, revelando-se como entidade viva e atuante na construção de sentidos e memórias associadas ao mundo dos mortos.

Palavras-chave: Arquiteturas funerárias, matérias construtivas, visibilidade, interligação simbólica entre rochas e minerais e as práticas funerárias

\begin{abstract}
Funerary architectures and material constructions. The case study of the litle cairn of Laceiras do Covo 3, Vale de Cambra (Central-North of Portugal).

It is intended with this article to discuss the results of the archaeological works carried out in the funerary monument of Laceiras do Covo 3. This is a sepulcral structure, probably inserted in the Bronze Age, located in the parish of Arões, in the county of Vale de Cambra. This monument reveals itself particularly interesting by the intentional polychromy in the material used in its construction and by the careful disposition of the lithological elements of the tumulus, where nothing seems to be random. These characteristics suggest the intention to keep visible the space of the dead, as well as a symbolic interconnection between rocks and minerals and practices related to death. In the line of Tim Ingold (2000) we also consider that the material of the monument would be bearer of certain properties, revealing itself as a living entity and active in the construction of meanings and memories associated with the world of the dead.
\end{abstract}

Keywords: Funerary architectures, matters of construction, visibility, symbolic interconnection between rocks and minerals and practices related to death.

\section{INTRODUÇÃO}

O tumulus de Laceiras do Côvo 3 foi descoberto em prospeção realizada por Fernando Pereira da Silva e, referido pela primeira vez, no relatório de escavação do tumulus 2 de Laceiras do Covo ${ }^{1}$ (PEREIRA DA SILVA 1997). Foi posteriormente descrito, por Queiroga (2001) e por Silva et al. (2009) de forma sumária. No âmbito da dissertação de mestrado $^{2}$ da primeira subscritora, integrada no projeto Enardas ${ }^{3}$, foi decido estudar o monumento de forma detalhada, o que implicou trabalhos de relocalização e de escavação. Numa primeira fase, analisou-se o microcontexto físico e ambiental da área envolvente ao monumento, as condições naturais de acesso ao local, o alcance visual que se tem a partir dele e o contexto etnográfico da área. Numa segunda fase, iniciou-se a escavação do imóvel, que decorreu em intervenções pontuais com a duração de cerca de quatro semanas, entre 2012 e 2013. As escavações foram solicitadas à tutela por Ana M. S. Bettencourt tendo sido realizadas com os restantes subscritores deste trabalho, em estreita colaboração ${ }^{4}$. No âmbito da escavação foi nossa

(1) Mestranda em Arqueologia da Universidade do Minho, Departamento de História, Instituto de Ciências Sociais, Campus de Gualtar, 4710-057, Braga. Email: editesa@gmail.com

Departamento de História da Universidade do Minho. Campus de Gualtar, 4710- 057 Braga, Portugal. Investigadora do Centro de Investigação Transdisciplinar, Cultura, Espaço e Memória - CITCEM/UM. Email: anabett@uaum.uminho.pt

(3) Departamento de Ciências da Terra da Universidade do Minho, Campus de Gualtar, 4710-057 Braga, Portugal; Centro de Ciências da Terra/Centro de Geologia da Universidade do Porto - CCT/CGUP/UM. Email: pedropimentasimoes@gmail.com

PEREIRA DA SILVA, 1996. Relatório da escavação arqueológica da Mamoa 2 de Laceiras do Covo (Arões, Vale de Cambra) - 1996. Oliveira de Azeméis (Dactilografado).

(Dactilografado).

Espaços Naturais, Arquiteturas, Arte rupestre e Deposições na Pré-história Recente da Fachada Ocidental do Centro e Norte Português: das Ações aos Significados - ENARDAS (PTDC/HIS-ARQ/112983/2009)

Nos trabalhos de campo participaram, ainda, os arqueólogos Ana Catarina Gomes, Diana Amorim, Fábio Soares, Joana Ferreira, Joana Rita Inocêncio, Luís Silva, Maria Lúcia Araújo e Vítor Silva, assim como os alunos do curso de arqueologia da Universidade do Minho, Carlos Fernandes, Joana Pereira, Luiza Câmpera, Óscar Santos e Rogério Alves. A todos manifestamos o nosso agradecimento pela cooperação e empenho. 
intenção estudar, de forma detalhada, a estrutura arquitetónica do monumento, a análise litológica dos seus constituintes e os seus contextos de origem o que, em associação com o seu contexto espacial, contribuiu para aumentar os conhecimentos sobre as conceções da morte e os modos de vida da população da Idade do Bronze que frequentaram os cumes da serra da Freita.

Para a interpretação dos dados partimos quer da base empírica quer de várias premissas teóricas a saber: que a distinção entre natureza e cultura resulta de uma perspetiva modernista e ocidental de ver o mundo (cf. INGOLD 2000); que a manufatura que, com elas, se interrelacionam (Cf. INGOLD 2000). A este propósito diz Ingold (2008: 88) artefacts emerge - like the forms of living beings - within the relational contexts of the mutual involvement of people and their environments. Nesta perspetiva, construir num determinado espaço é criar novos cenários de significação no mundo em que se habita, se vive e se experiência, ou seja, é dweling the landscape (INGOLD 2000). Numa perspetiva mais animista, a relação entre "Homem, Matéria e Natureza" dá origem a objetos e construções que contêm propriedades e que serão parte integrante $\mathrm{e}$ determinante das práticas culturais e religiosas levadas a cabo numa determinado espaço (BRADLEY 2000; THOMAS 2004; TILley 2007). Considerámos, ainda, os contextos funerários como cenários manipuladores onde não está patente a "biografia" do morto, mas representações ideológicas coletivas, pelo que estes constituem um veículo transmissor de valores e posturas morais perante a vida e perante a visão da humanidade, constituindo, portanto, um reflexo dos vivos (PEARSON 1999).

\section{LOCALIZAÇÃO ADMINISTRATIVA, CONTEXTO FÍSICO E AMBIENTAL}

O tumulus de Laceiras do Côvo 3 pertence ao lugar da Felgueira, freguesia de Arões, concelho de Vale de Cambra, distrito de Aveiro. As coordenadas geográficas, segundo o sistema WGS 84 são as seguintes: N. $40,84353^{\circ}$, W. $008.27222^{\circ}$ (Fig. 1).

Em termos geomorfológicos localiza-se a cerca de $1000 \mathrm{~m}$ de altitude no extremo sudoeste do planalto da Serra da Freita, num pequeno patamar de um esporão virado a sudeste, definido entre duas linhas de água. O local situa-se, ainda, num zona de cumeada aplanada e de portela que separa a vertente noroeste da serra dominada pelo rio Caima, da vertente sudeste dominada pelo rio Teixeira, ambos afluentes do rio Vouga.

O túmulo localiza-se numa estreita faixa de xistos de direção sudeste-noroeste, existente no seio de granitos de duas micas que integram o maciço granítico Junqueira-Serra da Freita, com idade de $308 \mathrm{Ma}$ (AGUADO et al. 2005). Os xistos são formados na sua maioria por filitos embora

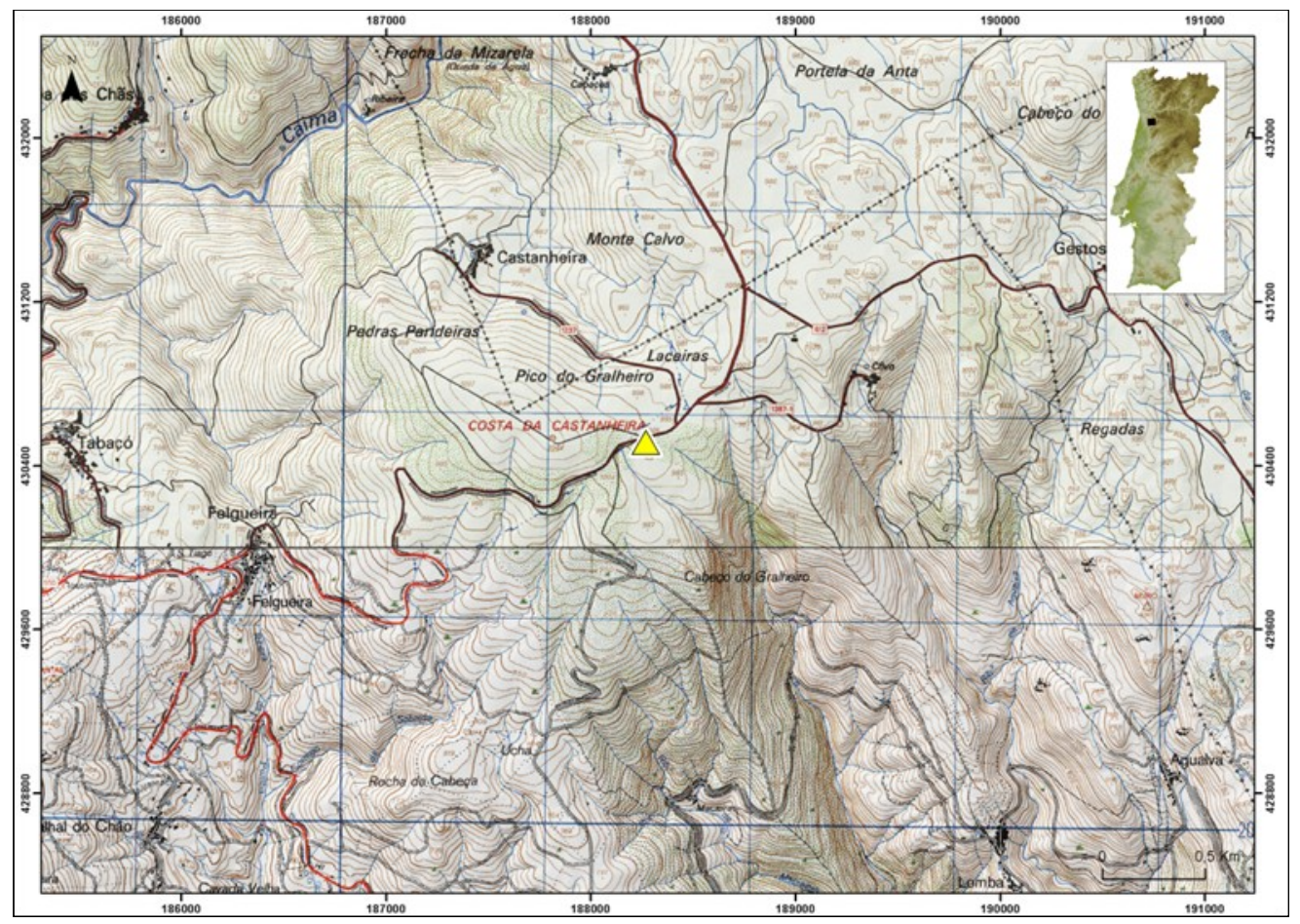

Fig. 1. Localização do monumento de Laceiras do Covo 3 na Carta Militar de Portugal, $\mathrm{n}^{\circ}$ 155, escala 1: 25000. Figure 1. Location of Laceiras do Côvo 3 at the Portuguese Military Chart, sheet 155, scaled 1:25 000. Grid map: $1 \mathrm{~km}$. 
também ocorram micaxistos, principalmente no contacto com os granitos. Nos xistos pode ainda observar-se a ocorrência de quartzo leitoso de exsudação, por vezes com filmes de goethite ou de ilmenite em patines ou fissuras. A par dos xistos existe, na proximidade do túmulo, a ocorrência de turmalinitos com níveis finos de quartzo que lhe conferem um aspeto gnaíssico. É ainda de referir a ocorrência de possantes filões de quartzo de cor branca (quartzo leitoso), por vezes com tons levemente alaranjados devido à presença de algum ferro na sua constituição. Observa-se, ainda, nos xistos a ocorrência de pequenos níveis de anfibolitos (Fig. 2).

Embora na Carta Geológica de Portugal 13-D Oliveira de Azeméis não esteja marcada nenhuma ocorrência de cassiterite, o testemunho de antigos mineiros comprovaram a referida ocorrência mineral a cerca de $500 \mathrm{~m}$ para sudoeste do túmulo, provavelmente em depósitos coluvionares. Atualmente ainda se podem observar testemunhos dessa antiga actividade mineira ocorrida nos anos 40 do século XX, segundo entrevista efetuada a moradores no lugar da Felgueira. Do lado direito e esquerdo da estrada municipal que dá acesso à aldeia da Castanheira, a menos de $1 \mathrm{Km}$ para noroeste do túmulo em estudo, ainda é possível ver cortas e a escombreira da lavaria.

O monumento implanta-se atualmente numa área de solos magros onde nasce vegetação arbustiva (tojo, carqueja e urze), usada para a prática da pastorícia de bovinos e caprinos.

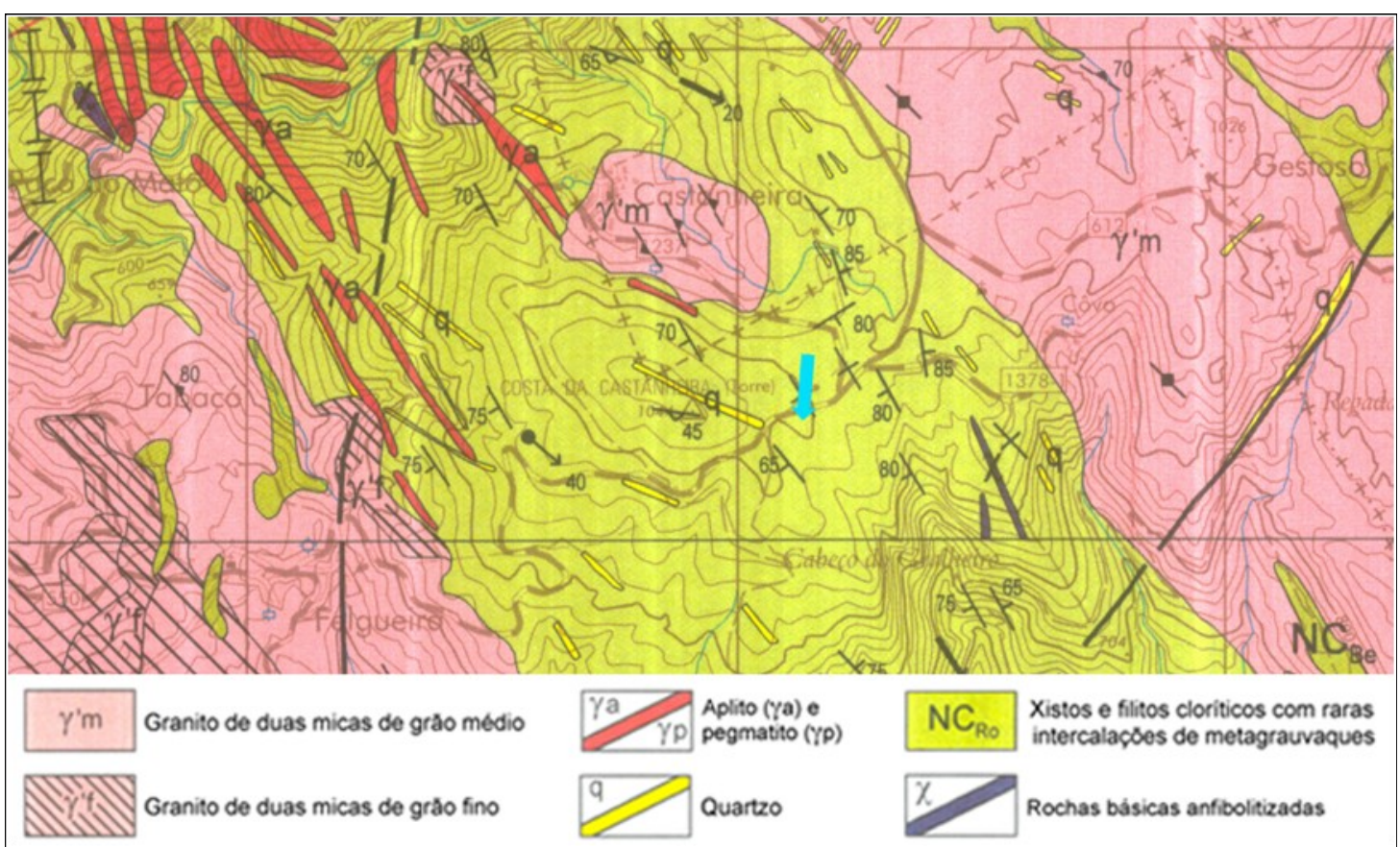

Fig. 2. Localização do monumento de Laceiras do Côvo 3 (seta azul), na Carta Geológica de Portugal, 13 D- Oliveira de Azeméis, na escala 1:50 000 (Pereira et al., 2006). Os quadrados correspondem a $2 \mathrm{Km}$.

Figure 2. Location of Laceiras do Côvo 3 (blue arrow) at the geological map 13D-Oliveira de Azeméis (Pereira et al., 2006) scaled at 1:50 000. Grid map: $2 \mathrm{~km}$.

\section{ESCAVAÇÃo}

\subsection{Metodologia}

A metodologia aplicada na descrição e escavação deste monumento partiu das premissas teóricas adotadas.

A intervenção arqueológica em Laceiras do Côvo 3 iniciou-se com a montagem da respetiva quadrícula de definição da área de escavação, de modo a abranger os limites do derrube da estrutura ${ }^{5}$. Foi definida uma área com a dimensão de $6 \mathrm{~m}$ por $6 \mathrm{~m}$. A subdivisão foi feita em quadrados de $1 \mathrm{~m}$. Para a tiragem de cotas foi estabelecido o ponto 0 convencional, que foi definido no topo de um bloco de quartzo a cerca de $3 \mathrm{~m}$ para sudeste do monumento, o qual considerámos não ser passível de sofrer oscilação de cota. Desta feita procedeu-se à limpeza inicial do monumento, que se encontrava parcialmente coberto por vegetação herbácea, visto o local ter sofrido um incêndio recente.

A quadrícula foi enquadrada numa grelha de letras e algarismos. Traçou-se um eixo sul-norte a partir do qual se estendeu uma malha. A escavação foi efetuada pela definição de unidades estratigráficas.

Seguiu-se uma fase de limpeza e decapagem da camada humosa, após a qual se fotografou e desenhou o plano inicial, à escala $1 / 20$ (Fig. 3).

5 Foi solicitada à Câmara Municipal de Vale de Cambra o levantamento topográfico da área e a implantação da quadrícula no mesmo. 


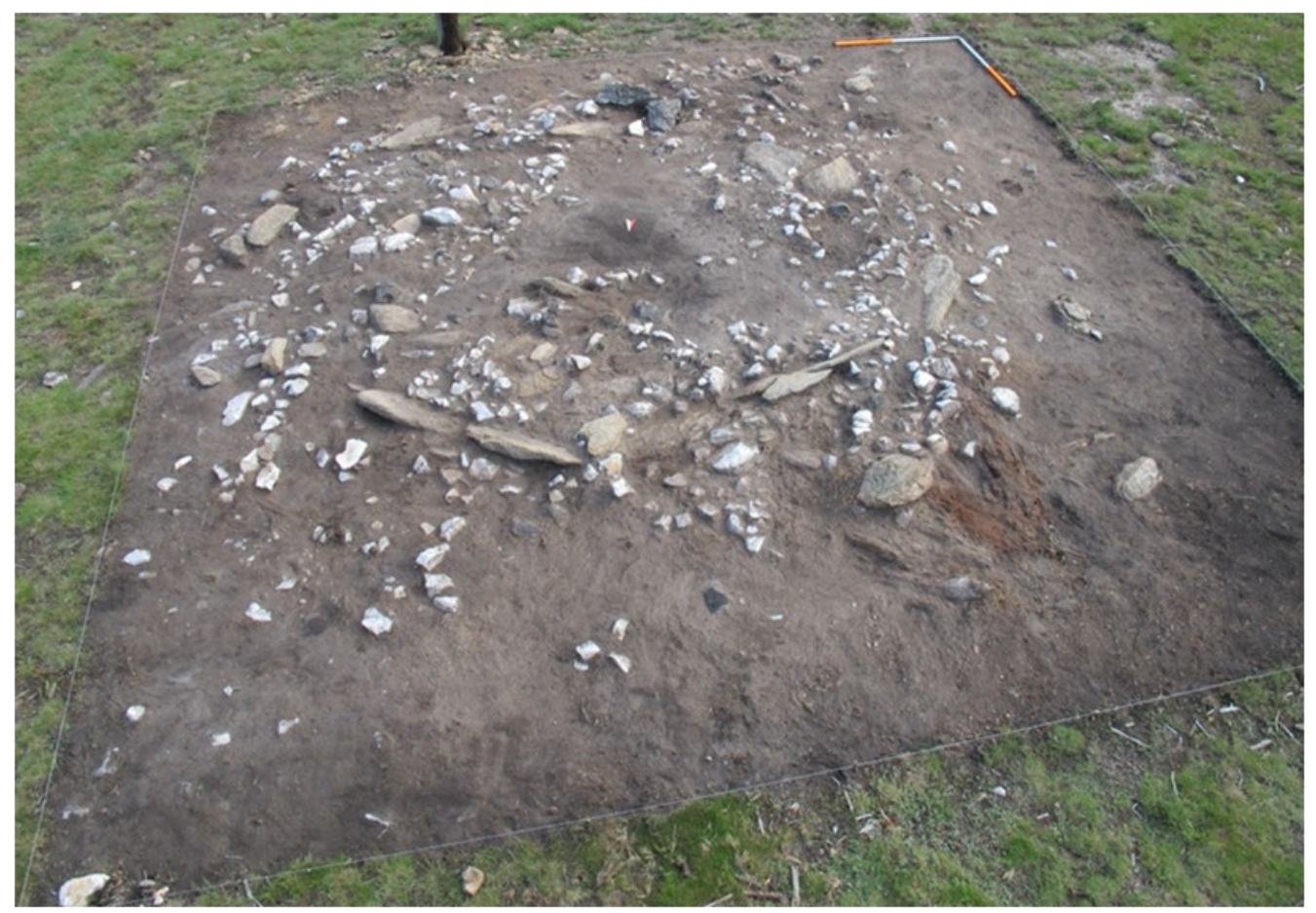

Fig. 3. Laceiras do Côvo 3 após decapagem inicial.

Figure 3. Laceiras do Côvo 3 after the first cleaning.

No desenho do plano inicial foi dada particular atenção à distinção dos materiais constituintes do monumento para que a aparente policromia intencional existente ficasse bem documentada. Para isso, foram utilizadas colorações diferentes para o xisto, para o quartzo leitoso e para os turmalinitos com níveis de quartzo (Fig. 4). Posteriormente, deu-se início à segunda decapagem que teve como objetivo delimitar o contorno do tumulus, tendo-se procedido à remoção de algumas pedras do derrube por se encontrarem fora do monumento e precisar melhor as suas características arquitetónicas. Nesta fase, surgiram vários calhaus de quartzo concentrados, fora do limite sul do tumulus (quadrados B6 e C6), pelo que foi decidido definir muito bem esta zona, para confirmar se provinham de escorrências do tumulus 3 de Laceiras do Côvo ou se fariam parte de outra estrutura arqueológica que estivesse adossada a este monumento. Com o decorrer dos trabalhos verificou-se que eram derrubes da couraça porque as terras existentes entre e sob os quartzos correspondiam à camada humosa, ou seja, à UE 01 e à UE 02.

Paralelamente foi iniciada a escavação da área central do monumento, onde supostamente teria existido uma câmara funerária. Esta escavação iniciou-se por parte do quadrado $\mathrm{C} 4 \mathrm{e} \mathrm{a}$ totalidade do D4. Pelo facto de esta área estar violada até à rocha de base considerámos pertinente prolongarmos a escavação para parte dos quadrados C5 e D5 por forma a observarmos toda a área passível de poder ter contido uma câmara funerária.
A escavação terminou quando encontrámos indícios do cairn in situ.

Todas as terras extraídas destes quadrados foram crivadas na sua totalidade com crivos de malha muito fina. Não foram recolhidas amostras de carvões para análises de diferentes tipos, pois estes só ocorreram em unidades estratigráficas correspondentes a sedimentos revolvidos. Todas as fases foram objeto de registo fotográfico e gráfico, geral e de pormenor. No plano final do monumento, à semelhança de todos os desenhos, registámos, com diferentes colorações, todos os tipos de rochas presentes na estrutura funerária.

\subsection{Estratigrafia}

A UE 00, a primeira a ser descrita, corresponde à camada humosa. Abrange o topo do montículo do monumento, bem como a sua área periférica. Tinha uma coloração castanha e amarelada, em determinadas zonas, resultado da deterioração do xisto de base. Apresentava composição limosa, com pouca compacidade. Alguns calhaus e blocos de micaxisto, quartzo, etc. deslocados do tumulus ou fazendo parte do seu derrube ou violação foram considerados como pertencentes a esta UE. Existiam, igualmente, raízes, radículas e carvões de incêndios recentes.

Na segunda decapagem do monumento e, após a remoção dos calhaus e blocos descontextualizados, surgiu a UE 01. Esta circunscrevia-se à área interior do tumulus e continha mais calhaus de quartzo, anteriormente tapados pela camada vegetal. Desta 


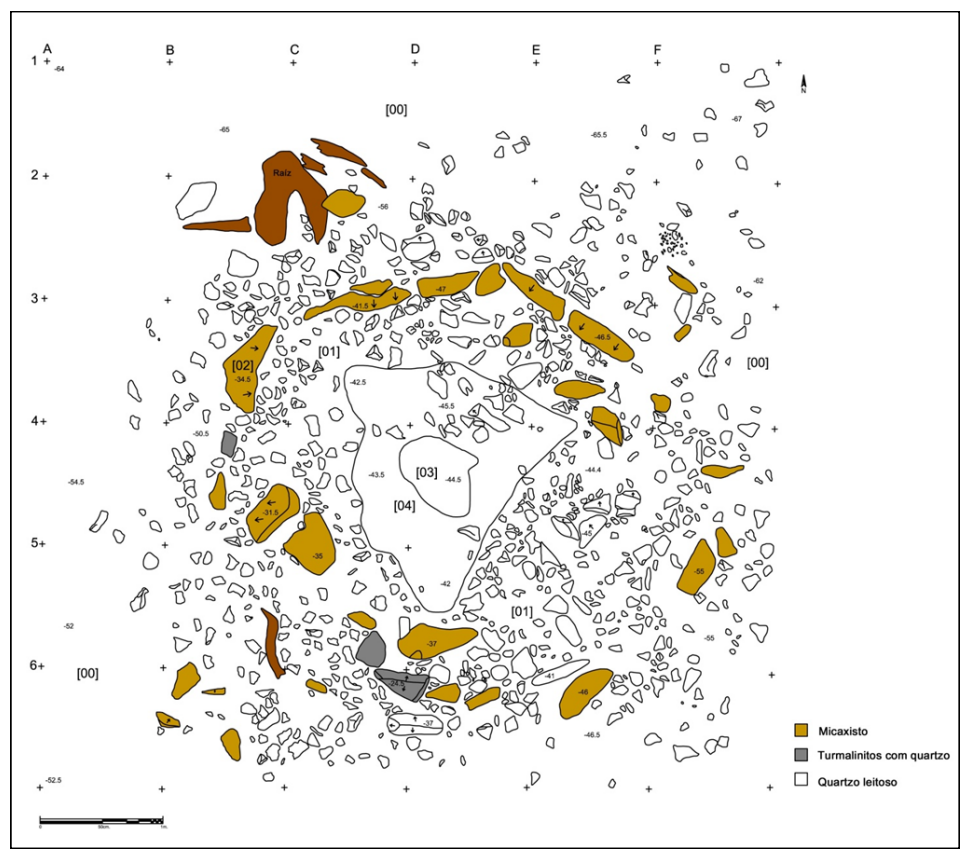

Fig. 4. Planta inicial do monumento.

Fig. 4. Initial plan of the monument.

forma, foi possível confirmar os limites do monumento em si.

A UE 02 corresponde ao tumulus, com terras mais compactas do que as da UE anterior e com uma coloração mais amarelada. Tinha inúmeros blocos e calhaus de micaxisto, de quartzo leitoso e de turmalinitos com níveis finos de quartzo.

A UE 03 encontra-se na zona central do monumento. Apresentava coloração negra, composição limosa e alguma compacidade. A sua coloração resultou de um incêndio recente ocorrido na região. Tinha, portanto, inúmeros carvões e raízes queimadas.

A UE 04 surgiu depois da remoção da camada de incêndio, na zona central do monumento. Era bastante compacta, de composição arenosa e de coloração cinzenta. Era, também, pouco significativa e resultante, ainda, de sedimentos perturbados pelo referido incêndio. Tinha alguns calhaus de quartzo.

A UE 05 foi a penúltima camada a ser registada na área central. Apresentava coloração castanha escura, menor compacidade do que a anterior e composição mais limosa. Aqui surgiram fragmentos muito pequenos de xisto e de alguns carvões concentrados. Os calhaus de quartzo presentes ocorriam até ao substrato geológico e encontravam-se desordenados, o que faz levantar a hipótese de que seriam resultado de escorrências do tumulus aquando da violação da área central. Alguns destes quartzos, especialmente os que surgiram nos quadrados E4 e E5, pela sua dimensão destacada em relação aos outros, poderiam ter funcionado como contrafortes de uma possível câmara em cista, facto que o demasiado revolvimento da área da câmara não permite confirmar (cf. Fig. 4).

As UE's 06a e 06b são idênticas mas surgiram em duas áreas distintas: na base da área central, nos quadrados D4 e C4, nas imediações dos perfis nortesul e oeste-este, respetivamente. Trata-se de uma terra amarelada, muito argilosa e de grande compacidade (Fig. 5).

A UE 06c é idêntica às UE's 06a e 06b. É visível nos limites norte e noroeste do monumento, no quadrado $\mathrm{C} 3$ e na base de vários blocos de micaxisto que nela se fincam de forma oblíqua.

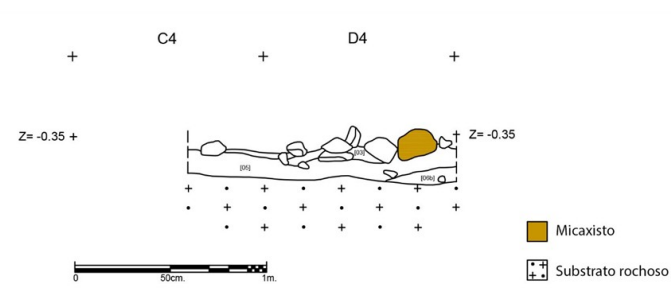

Fig. 5. Perfil oeste-este da área central do monumento. Fig. 5. West-east section of the central area of the monument.

\subsection{Espólio}

Não foi detetado qualquer tipo de espólio in situ ou no crivo.

\subsection{Ecofactos}

Os diferentes carvões recolhidos não foram analisados por terem sido extraídos de sedimentos revolvidos, mais concretamente das unidades estratigráficas 03,04 e 05. 


\section{RESULTADOS}

\subsection{O tumulus}

A intervenção ao monumento revelou um tumulus de contorno praticamente circular, com cerca de $3.70 \mathrm{~m}$ no eixo este-oeste, $3.74 \mathrm{~m}$ no eixo norte-sul e $0.40 \mathrm{~m}$ de altura. Este montículo era rodeado por um anel periférico formado por blocos de xistos colocados de forma oblíqua para o interior como estratégia de contenção da estrutura (Fig. 6).
Estes mediam entre 40 a $90 \mathrm{~cm}$. Nos casos melhor preservados verificou-se que estavam fincados numa camada de argila de preparação e nivelamento do solo, colocada por baixo de todo o monumento (UE's 6a, 6b e 6c), e escorados com pequenos calhaus de quartzo imbricados que ali foram colocados de forma a servir-lhes de cunha (Fig. 7).

Na composição do montículo verificou-se uma grande variedade de rochas e de minerais o que lhe conferiu uma grande policromia e brilho.

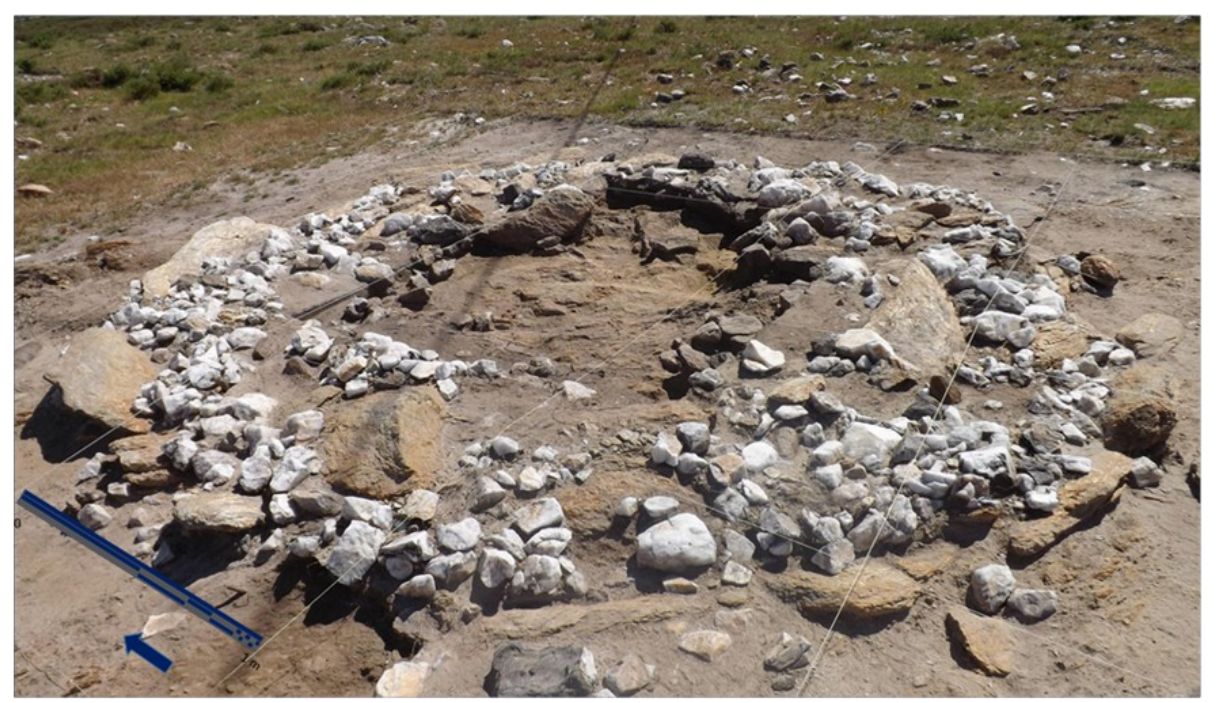

Fig. 6. Vista geral do monumento depois da decapagem e da escavação da área central. Visto de sudoeste. Fig. 6. General view of the monument after soil stripping. Picture from Southwest.

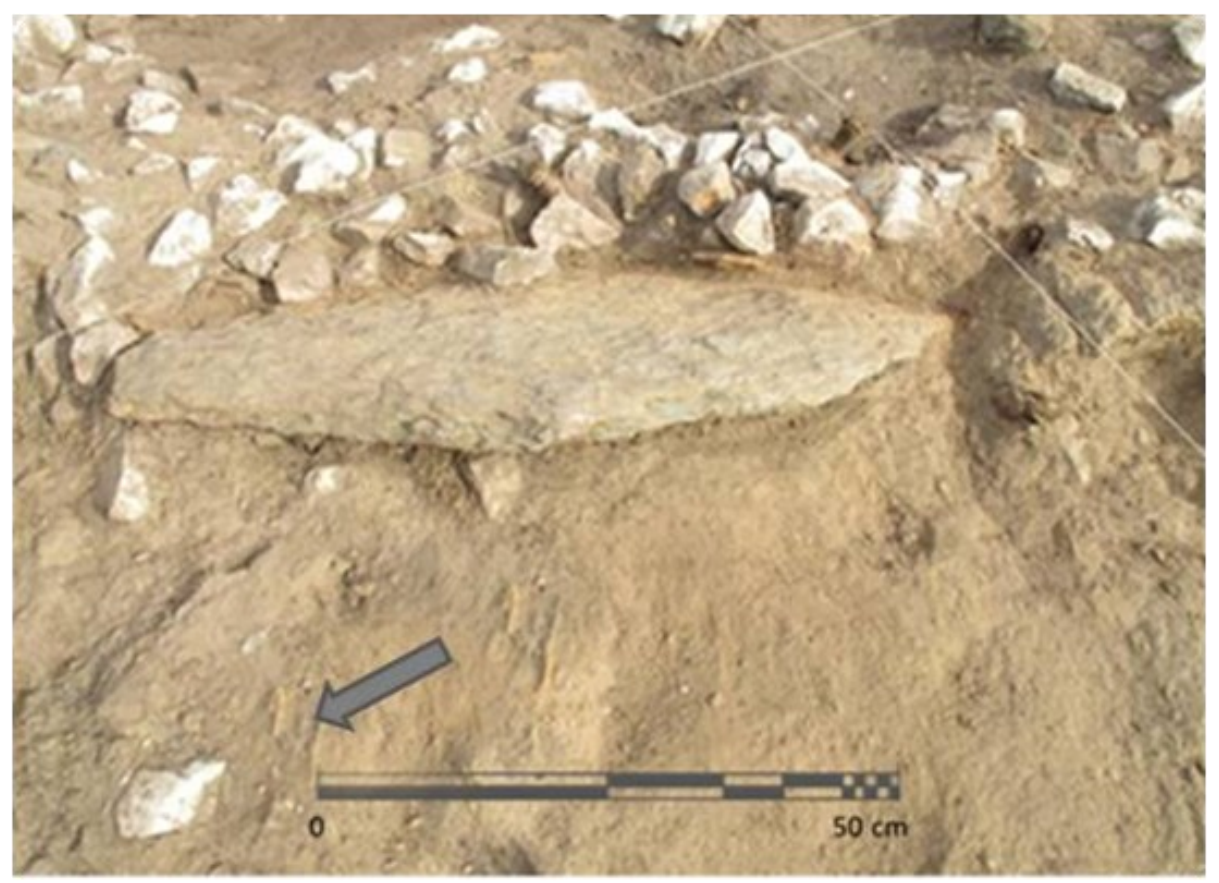

Fig. 7. Detalhe de uma das lajes de micaxisto da extremidade do monumento, fincada na UE $6 c$, de forma oblíqua para o interior. Podem ver-se, igualmente, alguns calços de sustentação da mesma.

Fig. 7. One of the schist's slab that surrounds the monument half embedded into a silt layer (6c). We can also see some wedges that support the slab. 
Este continha na sua maioria blocos e calhaus de quartzos leitosos, alguns quartzos alaranjados, resultado da presença de óxidos de ferro, assim como de blocos e calhaus de xisto, que apresentavam tons acinzentados e alaranjados, com algum brilho, devido à presença de moscovite ou fibrolite na sua composição. Existiam, também, calhaus de xisto com inclusões de quartzo, turmalinitos com níveis finos de quartzo, que lhes conferem um aspeto gnaíssico, assim como um bloco de andaluzite a su-sudeste do tumulus, também com inclusões de quartzo, todos de origem local (Fig. 8).

Pela disposição de alguns blocos de xisto no interior do tumulus parece ter existido um segundo anel, neste caso intermédio. Esta hipótese é reforçada pela sua elevada concentração geralmente de menores dimensões que os xistos do anel periférico - visíveis a norte, nordeste, este, sudeste, sul, sudoeste e a oeste do tumulus. No entanto, a sua disposição algo desordenada não permite afirmar se se trataria, de facto, de um anel ou de elementos do cairn (Fig. 8).

Apesar dos processos pós deposicionais ocorridos no monumento é possível admitir que este foi criteriosamente pensado e executado, tendo exigido, por parte dos seus construtores, a escolha de determinadas matérias locais, com dimensões mais ou menos precisas, e uma disposição das mesmas que não foi aleatória.

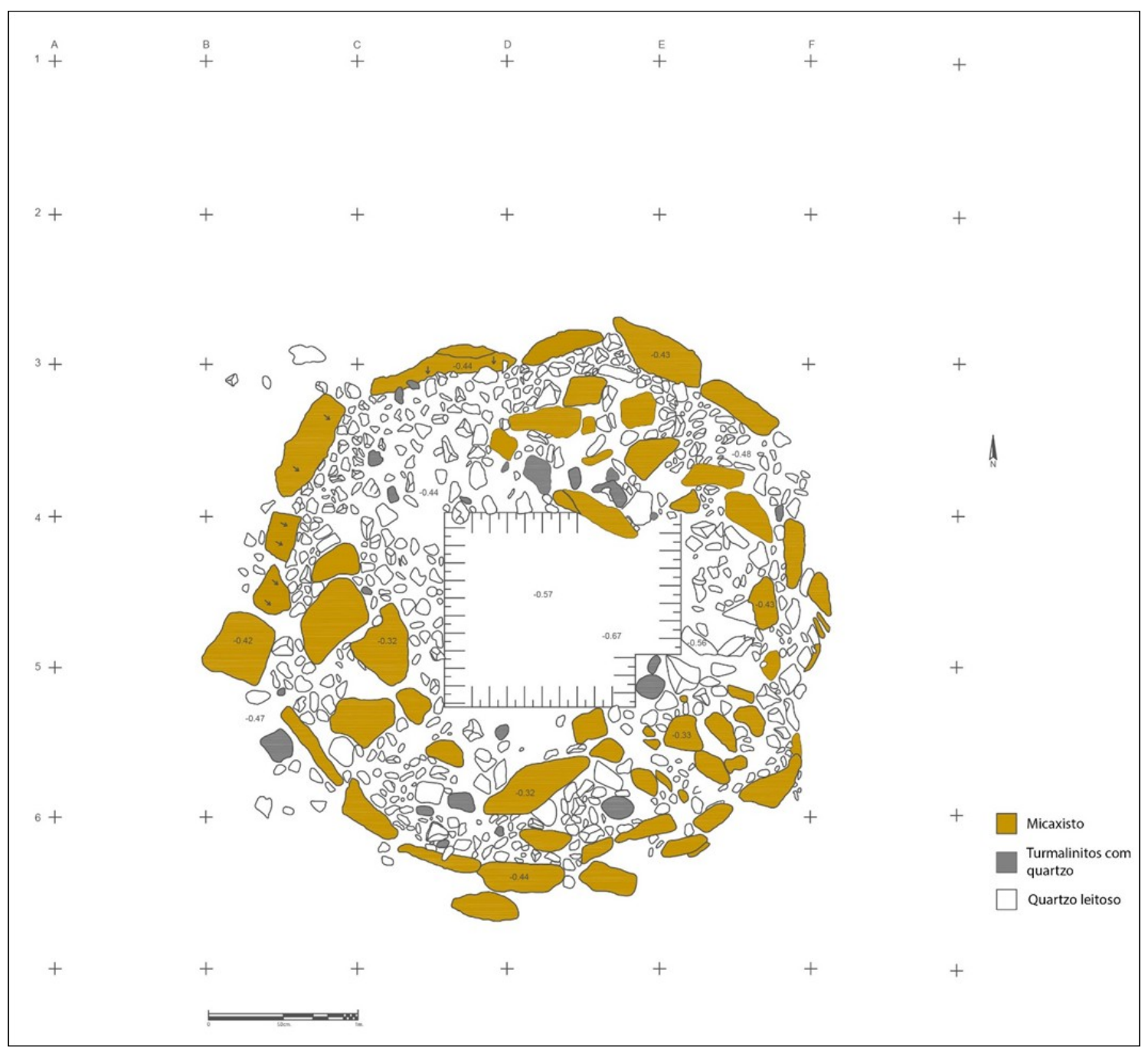

Fig. 8. Planta final do monumento de Laceiras do Côvo 3. No centro assinala-se a área de escavação até à rocha de base. No quadrante nor-noroeste pode ver-se um esteio da câmara in situ.

Fig. 8. General plan of the monument 3 of Laceiras do Covo. In the center we can observe the excavation area to the bedrock. In the NNW corner, we can see one of the slabs of the chamber, in situ. 


\subsection{A câmara}

A área central do monumento revelou-se muito revolvida, resultado da sua provável violação, pelo que a sua interpretação não é isenta de dúvidas (Fig. 9).

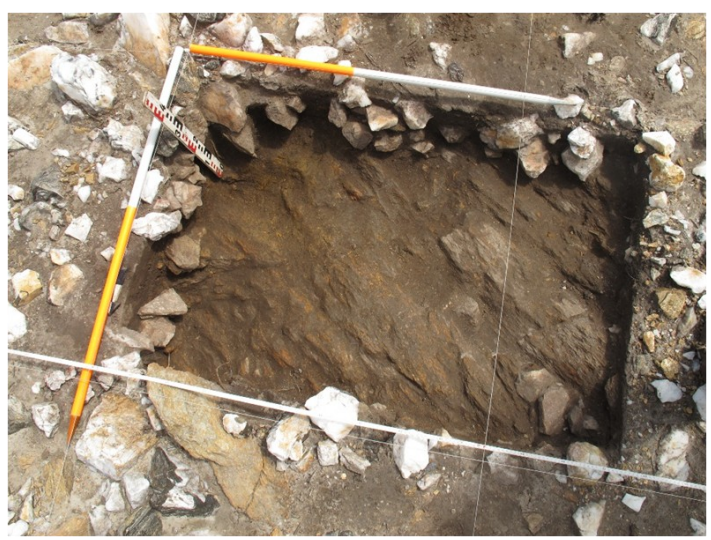

Fig. 9. Escavação da área central, quadrados D4 e C4 (da esquerda para a direita), onde se pode verificar que esta se encontrava bastante destruída. No canto nor-noroeste do quadrado D4 ainda se conserva um esteio in situ.

Fig. 9. Central area. Squares D4 and C4 (from left to right). Although this area is already very destroyed we can still observe a original slab in the corner NNW of the square D4.

No entanto, a identificação, nos quadrados D3 e D4, de uma laje de micaxisto, in situ, disposta na vertical, calçada com dois pequenos calhaus, também de micaxisto, e assente na camada de argila que cremos de preparação do local onde se implantou o monumento (UE's 6ae 6b), levou a considerá-la como um possível esteio de uma pequena cista, que aqui teria existido (Fig. 10). Pelas dimensões desta laje - cerca de $32 \mathrm{~cm}$-, a câmara não poderia ser muito alta. Pela sua disposição no monumento, algo descentrada, assim como pela disposição dos quartzos do tumulus que aparentam estar in situ, a cista poderia ter sido retangular e com uma orientação de nordeste para sudoeste ou de noroeste para sudeste.

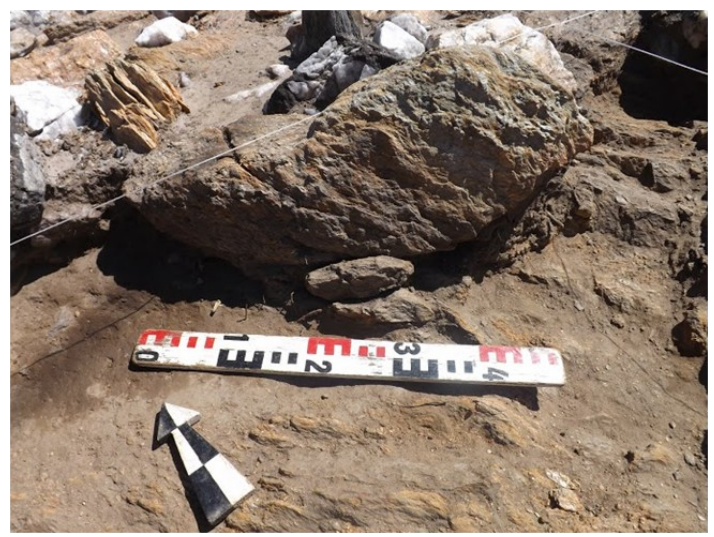

Fig. 10. Pormenor do esteio in situ, existente no quadrado D4 e parte do D3.

Fig. 10. Detail of a possible orthostat from the chamber (square D4).
Foram identificadas algumas lajes de xisto deslocadas, quer sobre o tumulus quer na sua periferia, que poderiam corresponder a esteios de uma cista. Duas delas encontravam-se nos quadrados C4 e B4, sendo a do quadrado B4 a que se encontrava fora dos limites do monumento.

\section{DISCUSS ÃO DOS RESULTADOS E INT E R P R E T AÇÕ ES}

Por ter sido impossível encontrar matéria vegetal passível de datação radiométrica a cronologia deste monumento só pode ser efetuada por paralelos com outras estruturas similares existentes no Centro-Norte de Portugal. Referimo-nos, por exemplo, aos tumuli muito pequenos e muito baixos, como por exemplo os da Senhora da Ouvida, em Castro Daire (CRUZ \& VILAÇA 1999) e da Casinha Derribada, em Viseu, (CRUZ et al. 1998) cujas datações efetuadas relevaram cronologias entre os finais do Bronze Médio e o Bronze Final, datas que admitimos como prováveis para este monumento.

A escavação do monumento 3 de Laceiras do Côvo revelou-nos uma estrutura com características muito particulares, apesar da sua aparente simplicidade, pois foi notória a intencionalidade em reunir diferentes matérias na sua construção que, embora de proveniência local, foram escolhidas criteriosamente pois só algumas das que se encontravam disponíveis no meio circundante foram usadas.

Tendo presente as premissas de que nas comunidades tradicionais a matéria não seria algo inerte mas sim uma entidade cheia de propriedades que lhes eram conferidas pelas comunidades, conforme defendem Ingold (2000) e Bradley (2000) e de que construir seria reunir elementos com diferentes significados num novo espaço significante (INGOLD 2000), cremos que os elementos litológi$\cos$ existentes no monumento transparecem uma profunda interação com o espaço que o rodeia, numa ação propositada que visou relacionar o sentido das rochas e dos minerais com os ritos e as práticas associadas à morte. Tais elementos seriam, provavelmente, portadores de determinado simbolismo, ou seja, seriam entidades vivas, simultaneamente resultantes e agentes do pensamento simbólico das comunidades da Idade do Bronze e, portanto, atuantes na construção e na manutenção da memória coletiva, traduzindo mensagens inteligíveis para quem frequentasse estes lugares e fosse portador dos códigos para a sua interpretação. Naturalmente que estas mensagens estão vedadas aos arqueólogos, mas é curioso pensar que, em todos os monumentos sob tumuli da Idade do Bronze identificados no Centro-Norte e no Norte de Portugal (Jorge 1980, 1982; JORGE 1988; Pereira DA SIlva 1997; CRUZ et al. 1998; CRUZ \& VILAÇA 1999; CRUZ 2001; Silva et al. 2009; SÁ 2014; VILAS BOAS 2014, entre outros), o quartzo está presente, o que certamente não será por acaso. 
Queremos ainda destacar a abundância de quartzos leitosos no montículo de Laceiras do Côvo 3, assim como dos micaxistos, cuja policromia e brilho, quando atingidos por raios solares ou pelo luar, tornavam o monumento percetível e, por consequência, o lugar da morte visível. Adotando a perspetiva de Pearson (1999), cremos que tais características se interrelacionam com conceções do mundo que privilegiam a recordação dos mortos e a importância de manter "viva" a sua memória quer nas dinâmicas do quotidiano quer como modo de promover a coesão e a identidade grupal.

Em termos dos modos de vida cremos que os construtores deste tumulus seriam pastores, dadas as características geológicas e edáficas do seu local de implantação e, eventualmente, metalurgistas, dada a proximidade de cassiterite de coluvião, de fácil extração.

\section{AGRADECIMENTOS}

Este trabalho foi desenvolvido no âmbito do projeto de dissertação de mestrado da primeira signatária intitulado Contextos e práticas funerárias da Idade do Bronze na Serra da Freita, (Centro-Norte de Portugal) que, por sua vez, se insere na tarefa 4 do projeto Espaços Naturais, Arquiteturas, Arte rupestre e Deposições na Pré-história Recente da Fachada Ocidental do Centro e Norte Português: das Ações aos Significados - ENARDAS (PTDC/HIS-ARQ/112983/2009), financiado pelo Programa Operacional Temático Factores de Competitividade (COMPETE) e comparticipados pelo Fundo Comunitário Europeu FEDER.

Os autores agradecem aos revisores, as sugestões que contribuíram para melhorar este trabalho ; a Filipe Pereira a execução da figura 1, e a Maria João Amorim a tradução do resumo para inglês.

\section{BIBLIOGRAFIA}

AGUADO, B.V, AZEVEDO, M.R., SCHALTEGGER, U., MARTÍNEZ CATALÁN, J.R. \& NOLAN J. 2005. $\mathrm{U}-\mathrm{Pb}$ zircon and monazite geochronology of Variscan magmatism related to syn-convergence extension in Central Northern Portugal Lithos, 82 (12):169-184.

BRADLEY, R. 2000. An Archaeology of Natural Places. London and New York: Routledge.

CRUZ, D.J. 2001. O Alto Paiva. Megalitismo, diversidade tumular e práticas rituais durante a Pré-história recente. Coimbra: Universidade de Coimbra (Tese de Doutoramento - Policopiada).

CRUZ, D.J., GOMES, L.F.G. \& CARVALHO, P.M.S. 1998. O grupo de tumuli da Casinha Derribada (Concelho de Viseu). Conímbriga, 37: 5-76.
CRUZ, D.J. \& VILAÇA, R. 1999. O grupo de tumuli da "Senhora da Ouvida" (Monteiras/Moura Morta, Castro Daire, Viseu). Resultados dos trabalhos arqueológicos. Estudos Pré-históricos, 7: 129-161.

INGOLD, T. 2000. The perception of the environment. Essays in Livelihood, Dwelling and Skill. Londres/ Nova Iorque: Routledge.

JORGE, V.O. 1980. Escavação da Mamoa 1 de Outeiro de Gregos, Serra da Aboboreira, Baião. Portugalia, 1 (Nova série) : 9-28.

JORGE, V.O. 1982. Megalitismo do Norte de Portugal: distrito do Porto. Os monumentos e a sua problemática no contexto europeu. Porto: Universidade do Porto (Tese de Doutoramento - Policopiada).

JORGE, V.O.; ALONSO, F. \& DELIBRIAS, G. 1988. Novas datas de Carbono 14 para mamoas da Serra da Aboboreira. Arqueologia, 18: 95-98.

PEARSON, M.P. 1999. The Archaeology of Death and Burial. Great Britain: Sutton Publishing Limited.

PEREIRA DA SILVA, F.A. 1997 Contextos funerários da Idade do Bronze nos planaltos centrais do CentroNorte Litoral Português: tradição ou inovação? Atas do II Congresso de Arqueologia Peninsular. Neolitico, Calcolitico y Bronce (Zamora 1996). Vol. 2. Zamora: Fundação Rei Afonso Henriques, 605-620.

PEREIRA, E.; MOREIRA, A.; GONÇALVES, S.; RODRIGUES, J. \& SILVA, A.F. 2006. Carta e Noticia Explicativa da folha 13-D (Oliveira de Azeméis) da Carta Geológica de Portugal à escala de 1:50.000. Lisboa: INETI.

QUEIROGA, F.M. 2001. Inventário patrimonial de Vale de Cambra. I - Arqueologia. Vale de Cambra: Câmara Municipal.

SÁ, E. 2014. Contextos e práticas funerárias da Idade do Bronze na Serra da Freita, (Centro-Norte de Portugal). Braga: Universidade do Minho (Dissertação de Mestrado - Policopiada).

SILVA, A.M.; LEITE, J.N. \& ROCHA, D. 2009. Do espaço vivido ao espaço imaginado. Aproximações interdisciplinares à antropização dos planaltos da Freita (Arouca) do $3^{\circ}$ ao $1^{\circ}$ milénios a.C. In A.M.S. Bettencourt \& L.B. Alves (eds.) Dos montes, das pedras e das águas. Formas de interação com o espaço natural da pré-história à atualidade. Braga: CITCEM, APEQ, 95-114.

THOMAS, J. 2004. Archaeology and Modernity. London and New York: Routledge.

TILLEY, C. 2007. Materiality in materials. Archaeological Dialogues 14 (1): 16-20.

VILAS BOAS, L. 2013. Vale de Chão 1, Braga. Um tumulus da Idade do Bronze no Noroeste português, Estudos do Quaternário, 10:15-23. 